\title{
Single nucleotide polymorphisms in the promoter regions of Foxp3 and ICOSLG genes are associated with Alopecia Areata
}

\author{
G. Conteduca $\cdot$ A. Rossi - F. Megiorni - A. Parodi $\cdot$ F. Ferrera \\ S. Tardito $\cdot$ F. Battaglia $\cdot$ F. Kalli $\cdot$ S. Negrini $\cdot$ A. Pizzuti $\cdot$ \\ E. Rizza $\cdot$ F. Indiveri $\cdot$ D. Fenoglio $\cdot$ G. Filaci
}

Received: 24 July 2012/Accepted: 10 November 2012/Published online: 30 November 2012

(C) Springer-Verlag Italia 2012

\begin{abstract}
Alopecia areata (AA), an autoimmune disease affecting anagen stage hair follicles, is associated with polymorphisms in immune-related genes and with decreased number of $\mathrm{CD} 4+\mathrm{CD} 25+\mathrm{T}$ regulatory cells (Treg). Treg function is modulated by the forkhead box protein 3 (FOXP3) transcription factor and by inducible costimulator (ICOS), through interaction with the relative ligand, ICOSLG, whose genes are polymorphic. The aim of the study was to investigate whether specific single nucleotide polymorphisms (SNPs) of the rs2294020 FOXP3 and/ or rs378299 ICOSLG genes may be associated with AA. A case-control study was performed in 120 AA patients and 84 controls. SNPs were analyzed by gene sequencing. FOXP3 and ICOSLG gene expressions were analyzed by real-time PCR. Increased frequencies of the genotype carrying the FOXP3 rs2294020-3675(A) $[P=0.002$, OR (95 \% CI): $2.55(1.2-2.7)]$ or the ICOSLG rs378299-
\end{abstract}

G. Conteduca $\cdot$ A. Parodi - F. Ferrera $\cdot$ S. Tardito $~$ F. Battaglia

· F. Kalli · S. Negrini · F. Indiveri - D. Fenoglio · G. Filaci

Centre of Excellence for Biomedical Research,

University of Genoa, Genoa, Italy

\section{A. Rossi}

Department of Internal Medicine and Medical Specialities,

"Sapienza" University of Rome, Rome, Italy

F. Megiorni · A. Pizzuti

Department of Experimental Medicine, "Sapienza" University

of Rome, Rome, Italy

E. Rizza

Associazione Nazionale Alopecia Areata, Genoa, Italy

F. Indiveri · D. Fenoglio · G. Filaci $(\bowtie)$

Department of Internal Medicine, University of Genoa,

Genoa, Italy

e-mail: gfilaci@unige.it
509(C) $[P=0.01$, OR (95 \% CI): $2.21(1.1-2.6)]$ allelic variants were observed in AA patients than in controls. The genotype carrying the combination of the FOXP3 rs2294020-3675(A) and ICOSLG rs378299-509(C) allelic variants with the HLA DQB1*03 allele was more frequently present in AA patients than in controls $(P=0.04)$. The presence of the FOXP3 rs2294020-3675(A) or the ICOSLG rs378299-509(C) allelic variant was associated with reduced relative gene expression in AA patients. These data suggest that rs2294020 SNP of FOXP3 gene and rs378299 SNP of ICOSLG gene are associated with AA and with a reduced expression of the FOXP3 and ICOSLG genes in alopecia patients.

Keywords FOXP3 - ICOSL - Alopecia Areata - Single nucleotide polymorphisms - Autoimmunity $\cdot \mathrm{T}$ regulatory cells

\section{Introduction}

Alopecia Areata (AA) is a common skin disease, presenting with patchy hair loss, that affects approximately $1-2 \%$ of the general population [1-3]. AA is thought to be a tissue-specific autoimmune disease in which the mechanism of hair follicle destruction is immunologically mediated and controlled by activated $\mathrm{T}$ cells. Indeed, focal $\mathrm{T}$ lymphocytes infiltration [4] and deposition of hair folliclespecific autoantibodies [5] are present in anagen stage (growing) hair follicles. Susceptibility to AA has been referred to a polygenic complex $[6,7]$ comprising immune system genes coding for the human leukocyte antigens (HLA) or other immune-related gene products [8,9].

Regulatory $\mathrm{T}$ lymphocytes (Treg) are involved in the control of immune homeostasis by preventing autoimmune 
diseases [10]. Accordingly, in the $\mathrm{C} 3 \mathrm{H} / \mathrm{HeJ}$ mouse model for AA, Treg alterations have been observed in the skin and in draining lymph nodes [11]. Treg are commonly identified by the intracellular expression of forkhead box P3 transcription factor (FOXP3) that controls their development and function [12-15]. Mutations in human FOXP3 gene cause the IPEX syndrome [16], while its polymorphisms are associated with immune-mediated diseases [17-20].

Upon activation, Treg also express the inducible costimulator (ICOS) [21], a receptor that modulates their function [22]. ICOS binds to a unique ligand, ICOS ligand (ICOSLG) [23, 24]. In mouse models of autoimmunity, Treg expressing ICOS were shown to produce IL-10 and to control autoreactive $T$ cells in the invaded organ [25].

In this study, we explored the possibility that one specific single nucleotide polymorphism (SNP) in the promoter regions of FOXP3 (rs2294020) and ICOSLG (rs378299) genes could be associated with AA development. These SNPs were selected because they are the only non-intronic SNPs present with high frequency in the European population as reported in HapMap SNPs database (by UCSC and NCBI). Hence, these SNPs, being located in the promoter regions of FOXP3 and ICOSLG genes, may have a functional role directly correlated with the level of gene transcription and mRNA expression. Moreover, the presence and frequency of these polymorphisms were correlated with those of the DQB $1 * 03$ (DQ7) allele, which was recently recognized as a predisposing allele for the disease in the Italian population of AA patients [8]. The results show the strong association between AA and both FOXP3 and ICOSLG gene SNPs, whose presence also correlated with the DQB1*03(DQ7) allele. Moreover, they demonstrate that FOXP3 and ICOSLG gene expression is lower in AA patients than in healthy controls.

\section{Methods}

Patients and controls

One hundred and twenty patients affected with AA (27 males and 93 females, age ranging from 7 to 60 years, 43 with patchy AA, 48 with universalis AA and 28 with totalis AA) and 84 healthy controls ( 24 males and 60 females, age ranging from 15 to 75 years) from the same ethnic area were analyzed in a case-control study. Patients were recruited from the Department of Internal Medicine and Medical Specialities, 'Sapienza' University of Rome and from Associazione Nazionale Alopecia Areata. In Megiorni et al. [8] study, 96 of these patients had been already genotyped for HLA-DQB1*03(DQ7) polymorphism. The diagnosis of AA was performed according to specific criteria [26]. As controls, we enrolled healthy individuals who had not been affected by any autoimmune disease. The study was approved by the local ethics committee and has been performed in accordance with the 1964 Declaration of Helsinki and its later amendments. Informed consent was obtained from each participant.

\section{Power calculation}

We estimated that a sample size of 120 patients and 84 unmatched controls gives a power of $80 \%$ in detecting a difference of allelic frequency between cases and controls from 5 to $15 \%$ at a significance level of $5 \%$.

Gene sequencing

DNA was extracted from the peripheral blood cells by the DNA blood extraction kit (Qiagen, Valencia, CA.). The promoter regions of the FOXP3 and ICOSLG genes, containing the rs2294020 (A-3675G) and rs378299 (C-509T) SNPs, respectively, were PCR amplified using primers specifically designed to cover the -3925 to -3605 gene region for FOXP3 and the -566 to -229 gene region for ICOSLG gene. PCR conditions were optimized using various magnesium concentrations and annealing temperatures. Genomic DNA (100 ng) was run in each PCR. PCR products were purified from primers by the UltraClean PCR Clean-up Sample Kit (CABRU, Milan, Italy), automatically sequenced using the ABI BigDye Terminator Ready Reaction Mix (Applied Biosystems, Foster City, CA), and analyzed by an ABI 3130XL Genetic Analyzer (Applied Biosystems, Foster City, CA) according to the manufacturer's protocol.

Expression analysis of FOXP3 and ICOSLG genes

Twenty-five patients and 20 healthy controls were recruited for gene expression analysis. Peripheral blood mononuclear cells (PBMC) were isolated from heparinized venous blood by a standard Ficoll-Hypaque density centrifugation (Biochrom, Berlin, Germany).

FOXP3 (GenBank accession no. AF277993) and ICOSLG (GenBank accession no. AF289028) gene expression were analyzed by PCR and real-time PCR as follows. Forty-eight microliters of total RNA, isolated using the OMNIZOL RNA Isolation kit (EuroClone, PeroMilan, IT), was treated with $6 \mathrm{U}$ DNase I and reverse transcribed into cDNA using Oligo(dT) 20Primer and Superscript II Reverse Transcriptase (Invitrogen, Carlsbad, CA), followed by RNase $\mathrm{H}$ digestion. The amplification was performed in a Thermalcycler (Eppendorf, Hamburg, Germany) under following conditions: a single 
denaturation step at $94{ }^{\circ} \mathrm{C}$ for 3 min followed by either 35 (for ICOSLG) or 30 (for FOXP3 and GAPDH) cycles at $94{ }^{\circ} \mathrm{C}$ for $1 \mathrm{~min}$, then $62{ }^{\circ} \mathrm{C}$ for $1 \mathrm{~min}$ and $72{ }^{\circ} \mathrm{C}$ for 2 min, followed by a final extension step at $72{ }^{\circ} \mathrm{C}$ for $10 \mathrm{~min}$. The following oligonucleotide pairs were used (sense and antisense, respectively): FOXP3, $5^{\prime}$-TGACTTG TCTGTATACTCTTG- $3^{\prime}$ and $5^{\prime}$-TTTGCATGGTTCCCAC CTATCC-3'; ICOSLG, 5'-GCTCCGATGATCTCCAGGA

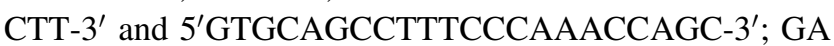
PDH, $5^{\prime}$-GAGCAACAGGAAGTGGCTGTG- $3^{\prime}$ and $5^{\prime}$-TA ATGCTTCCAGTTTACAAGTGGT-3'.

Quantitative real-time PCR was performed using the LightCycler thermocycler, the SYBR Green Master Mix (Roche Diagnostics, Ltd, Lewes, UK) and the above described primers. Reaction products were separated on a $1.2 \%$ agarose gel in TAE (40 mM Tris-acetate, $1 \mathrm{mM}$ EDTA) containing SYBR Safe DNA gel stain (Invitrogen, Carlsbad, CA). FOXP3 and ICOSLG PCR products were confirmed by sequence analysis. cDNA expression was normalized to glyceraldehyde-3-phosphate dehydrogenase (GAPDH) expression.

\section{Statistical analysis}

Statistically significant differences between genotype frequencies were assessed using univariate or multivariate analyses such as the Fisher's exact test for binary variables and the Student's t test for continuous variables. Odds ratio (ORs) and $95 \%$ confidence intervals (CIs) were calculated, and $P$ values lower than 0.05 were considered statistically significant. Analyses were performed using SPSS 13.0 and Graphpad Prism 4 softwares. A test for the Hardy-Weinberg equilibrium was performed by GenAlEx 6 software. Because multiple pair wise tests are performed on a single set of data, taking into account variables such as age, sex and alopecia subtypes, a Bonferroni-adjusted significance level of 0.05 was calculated to account for the increased possibility of obtaining falsepositive results.

\section{Results}

Frequency of rs2294020 FOXP3 and rs378299

ICOSLG SNPs in AA patients compared with controls

Genotypic and allelic frequencies of rs2294020 and rs378299 SNPs located in the promoter regions of FOXP3 and ICOSLG genes, respectively, were analyzed in AA patients and in healthy controls.

The distribution of the rs2294020 and rs378299 genotypes resulted in a Hardy-Weinberg equilibrium in both patients and controls (data not shown). Using Bonferroni's analysis, the patients and controls subgroups were significantly different for sex, age and Alopecia subtype (not shown). Hence, we could perform our analyses only on the total patient and control groups.

The possible genotypes for the rs2294020 FOXP3 SNP are either $\mathrm{G} / \mathrm{G}$ or $\mathrm{A} / \mathrm{A}$ for homozygous subjects, and $\mathrm{A} / \mathrm{G}$ for heterozygous individuals. Considering together all genotypes carrying the A allele, the frequency of A/A plus $\mathrm{A} / \mathrm{G}$ genotypes was higher in AA patients than in controls (Fig. 1a; Table 1). In order to calculate the frequency of the A allele in AA patients and in controls, female and male subjects were separately analyzed since the FOXP3 gene is located in X-chromosomes. The allelic frequency of the A allele was significantly higher in AA patients than in controls (Fig. 1b; Table 2).

The possible genotypes for rs378299 ICOSLG SNP are either $\mathrm{T} / \mathrm{T}$ or $\mathrm{C} / \mathrm{C}$ for homozygous subjects, and $\mathrm{T} / \mathrm{C}$ for heterozygous individuals. Considering together all genotypes carrying the $\mathrm{C}$ allele, the frequency of $\mathrm{C} / \mathrm{C}$ plus $\mathrm{C} / \mathrm{T}$ genotypes was higher in AA patients than in controls (Fig. 1c; Table 1). Moreover, the allelic frequency of the $\mathrm{C}$ allele was significantly higher in AA patients than in controls (Fig. 1d; Table 2).

Frequency of co-association of rs2294020 and rs378299 SNPs in the genome of AA patients and controls

Since each of the two studied SNPs resulted singularly associated with AA, we questioned whether the co-inheritance of the two SNPs in single genomes could be a more frequent event in AA patients than in controls. Here, we define as $\mathrm{AC}$ the allelic combination present in subjects carrying the rs2294020-3675(A) allele of the FOXP3 gene and the rs378299-509(C) allele of the ICOSLG gene. AC allelic combination frequency was significantly higher in subjects with AA than in healthy individuals (Table 3). No statistically significant differences between patients and controls were found when all the other possible allelic combinations were considered (Table 3).

Frequency of co-association of rs2294020 and rs378299 SNPs with HLA- DQB $1 * 03$ allele in the genome of AA patients and controls

Since the HLA DQB $1 * 03$ allele, coding for DQ7 heterodimers, has been recently recognized as a predisposing allele to $\mathrm{AA}^{8}$, the existence of an association between the combination of the rs2294020-3675(A) FOXP3, the rs378299-509(C) ICOSLG and the HLA DQB $1 * 03$ (DQ7) alleles with AA was analyzed. Here, we define as $\mathrm{AC}^{*} 03$ pos the allelic combination that is present in subjects who carry the rs2294020-3675(A), the rs378299$509(\mathrm{C})$ and the HLA-DQB1*03(DQ7) alleles. The 

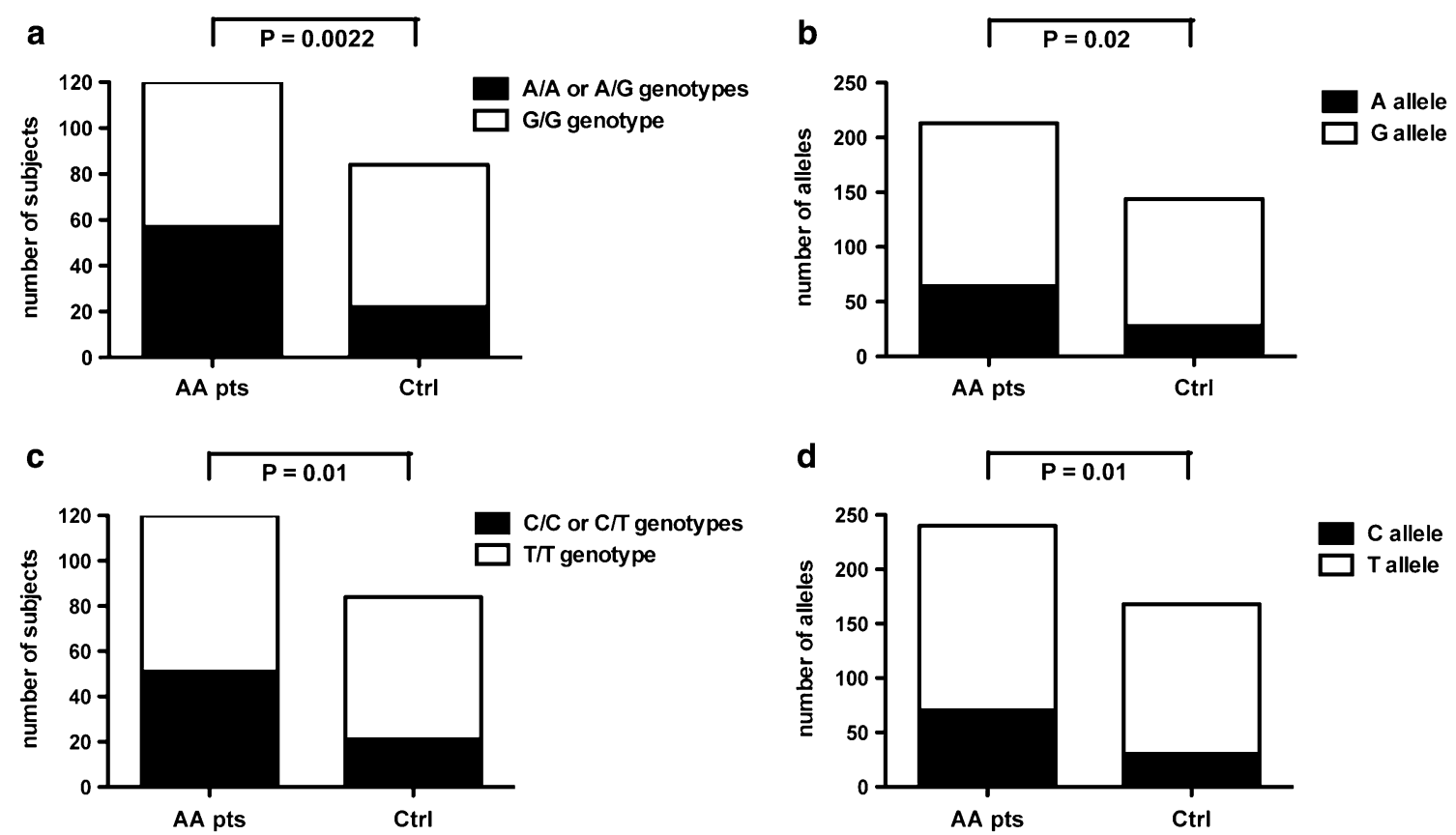

Fig. 1 Frequency of genotypes and allelic variants related to FOXP3 rs2294020 or ICOSLG rs378299 SNPs in AA patients (AA pts) and healthy controls (Ctrl). a FOXP3 rs2294020 genotypes; b FOXP3

Table 1 Association of AA with the rs2294020 A/A and A/G FOXP3 genotypes or rs $378299 \mathrm{C} / \mathrm{C}$ and C/T ICOSLG genotypes

\begin{tabular}{llll}
\hline Genotypes & Odds ratio & $\begin{array}{l}95 \% \text { confidence } \\
\text { intervals }\end{array}$ & $P$ value \\
\hline FOXP3 (A/A + A/G) & 2.55 & $1.2,2.7$ & 0.002 \\
ICOSLG $(\mathrm{C} / \mathrm{C}+\mathrm{C} / \mathrm{T})$ & 2.21 & $1.1,2.6$ & 0.01 \\
\hline
\end{tabular}

rs2294020 allelic variants; c ICOSLG rs378299 genotypes; d ICOSLG rs378299 allelic variants

frequency of $\mathrm{AC}^{*} 03$ pos allelic combination was significantly higher in AA subjects than in healthy individuals (Table 4). No statistically significant differences between patients and controls were found when all the other possible allelic combinations were considered (not shown).

rs2294020-3675(A) FOXP3 and rs378299-

509(C) ICOSLG alleles correlate with reduced FOXP3 and ICOSLG expression

Table 2 Association of AA with the rs2294020 FOXP3 A allele or the rs378299 ICOSLG C allele

\begin{tabular}{llll}
\hline Allele & Odds ratio & $95 \%$ confidence intervals & $P$ value \\
\hline FOXP3 $^{\text {a }}$ (A) & 1.77 & $1.0,2.9$ & 0.02 \\
ICOSLG (C) & 1.89 & $1.1,3.0$ & 0.01 \\
\hline
\end{tabular}

${ }^{a}$ Female and male subjects were separately analyzed since the FOXP3 gene is located in X-chromosomes. The number of female and male controls was 60 and 24, respectively; the number of female and male AA patients was 93 and 27, respectively

Since rs2294020 and rs378299 SNPs are located in the corresponding promoter regions of the FOXP3 and ICOSLG genes, it is reasonable to hypothesize that they could modulate the relative gene expression. Hence, we analyzed FOXP3 and ICOSLG mRNA levels in PBMC of AA patients and controls carrying or not the $-3675(\mathrm{~A})$ or $-509(\mathrm{C})$ alleles of FOXP3 and ICOSLG genes, respectively. Comparable levels of FOXP3 gene expression were observed in controls bearing the FOXP3 A allele

Table 3 Frequencies of rs2294020 and rs378299 allelic combinations in AA patients and controls

\begin{tabular}{|c|c|c|c|c|c|}
\hline Allelic combinations & Patients $(\%)$ & Controls $(\%)$ & OR & $(95 \% \mathrm{CI})$ & $P$ \\
\hline rs2294020-3675(G) + rs378299-509(T): GT & $31^{\mathrm{a}}$ & 56.4 & 1 Ref. & 1 Ref. & 1 Ref. \\
\hline rs2294020-3675(A) + rs378299-509(T): AT & 26 & 19 & 0.3 & $0.1,1.1$ & 0.08 \\
\hline rs $2294020-3675(\mathrm{~A})+\mathrm{rs} 378299-509(\mathrm{C}): \mathrm{AC}$ & 22 & 7 & 2.1 & $1.0,1.1$ & 0.05 \\
\hline rs2294020-3675(G) + rs378299-509(C): GC & 21 & 17.6 & 0.6 & $0.3,2.0$ & 0.1 \\
\hline
\end{tabular}

${ }^{a}$ Data are expressed as percentages of individuals carrying the indicated allelic combination among the total population of patients or controls 
Table 4 Frequencies of DQB1*03, rs2294020 and rs378299 SNPs association in genotypes of alopecia patients and controls

\begin{tabular}{llllll}
\hline $\begin{array}{l}\text { Genotype } \\
\text { combinations }\end{array}$ & $\begin{array}{l}\text { Patients } \\
(\%)\end{array}$ & $\begin{array}{l}\text { Controls } \\
(\%)\end{array}$ & OR & $(95 \% \mathrm{CI})$ & $P$ \\
\hline GT B $1 * 03 \mathrm{neg}^{\mathrm{a}}$ & $52^{\mathrm{e}}$ & 77.4 & 1 Ref. & 1 Ref. & 1 Ref. \\
$\mathrm{ATB} 1 * 03 \operatorname{pos}^{\mathrm{b}}$ & 17 & 11.2 & 5.1 & $1.4,18.6$ & 0.5 \\
$\mathrm{ACB} 1 * 03 \operatorname{pos}^{\mathrm{c}}$ & 20 & 4 & 1.5 & $0.3,8.0$ & 0.04 \\
$\mathrm{GCB} 1 * 03 \operatorname{pos}^{\mathrm{d}}$ & 11 & 7.9 & 2.3 & $0.5,10.6$ & 0.2 \\
\hline
\end{tabular}

${ }^{a}$ GTB $1 * 03$ neg $=$ rs2294020 $(\mathrm{G})+$ rs378299 $(\mathrm{T})+\mathrm{DQB} 1 * 03$ negative

b $\mathrm{ATB} 1 * 03$ pos $=$ rs2294020(A) + rs378299(T) + DQB $1 * 03$ positive

c $\mathrm{ACB} 1 * 03$ pos $=\mathrm{rs} 2294020(\mathrm{~A})+\mathrm{rs} 378299(\mathrm{C})+\mathrm{DQB} 1 * 03$ positive

${ }^{\mathrm{d}}$ GCB1 $* 03$ pos $=$ rs2294020(G) + rs378299(C) + DQB1*03 positive

${ }^{\mathrm{e}}$ Data are expressed as percentages of individuals carrying the indicated genotype combination among the total population of patients or controls

$(\mathrm{A} / \mathrm{A}+\mathrm{A} / \mathrm{G})$ or only the $\mathrm{G}$ allele (G/G) (Fig. 2a). Importantly, AA patients showed lower levels of FOXP3 expression independently from the carried FOXP3 A or G allele (Fig. 2b, c). However, AA patients homozygotes or heterozygotes for the rs2294020 A allele had lower FOXP3 mRNA levels than G/G homozygous patients (Fig. 2d).

Concerning ICOSLG gene expression, it was significantly lower in patients carrying the rs378299-509(C) allele
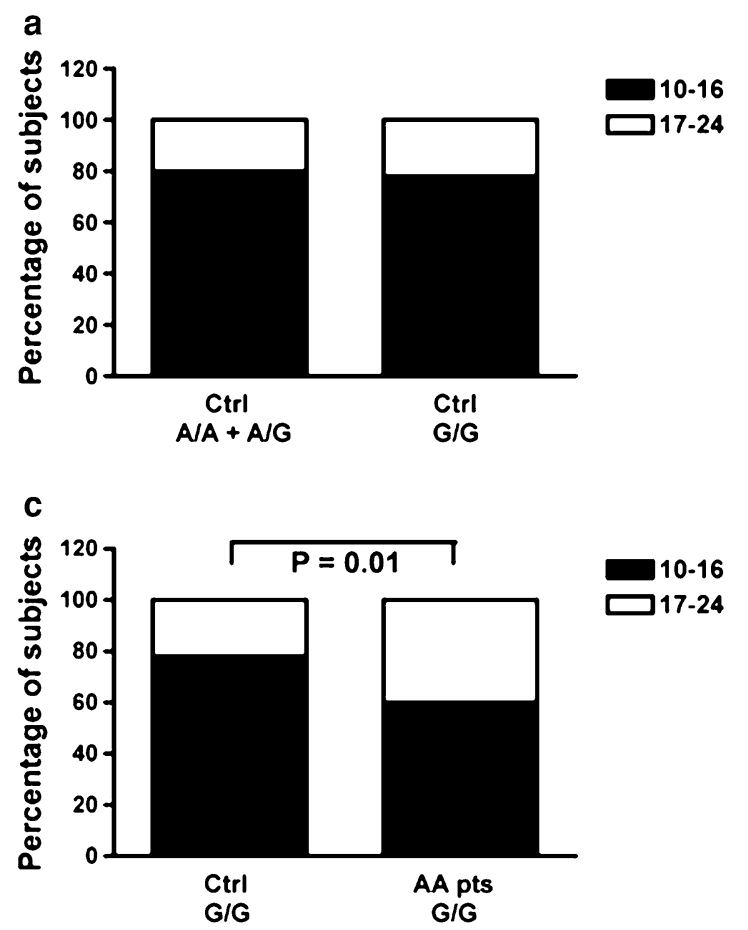

Fig. 2 Frequency of AA patients (AA pts) and healthy controls (Ctrl) carrying or not the A allelic variant of the FOXP3 rs2294020 SNP with high or low FOXP3 gene expression. Analyses were performed on 24 AA patients and 20 controls. Early and late ranges of cycle numbers of DNA amplification until threshold value were the following: 10-16 (black bars) and 17-24 (white bars). Analyses
$(\mathrm{C} / \mathrm{C}+\mathrm{C} / \mathrm{T})$ with respect to those carrying only the reciprocal $-509(\mathrm{~T})$ allele, although the opposite occurred in healthy controls (Fig. 3a, b, c). Interestingly, the expression of ICOSLG transcript was lower in patients homozygotes or heterozygotes for the rs378299-509(C) allele than in T/T homozygous cases (Fig. 3d).

\section{Discussion}

The results of this study show that: (a) the -3675 (A) allelic variant of the FOXP3 rs2294020 SNP and the $-509(\mathrm{C})$ of the ICOSLG rs378299 SNP are significantly more frequent, singularly considered or in reciprocal combination, in patients affected with AA than in healthy controls; (b) the association of rs2294020-3675(A) and rs378299509(C) allelic variants with the HLA DQB $1 * 03$ (DQ7) allele is significantly more frequent in patients affected with AA than in healthy controls; (c) rs2294020-3675(A) and rs378299-509(C) allelic variants are associated with a reduced expression of the relative genes in AA patients.

The discovery in the last decade of the relevant role played by Treg in the homeostatic control of the immune system elicited the hypothesis that autoimmune diseases could be related to altered regulatory functions by Treg
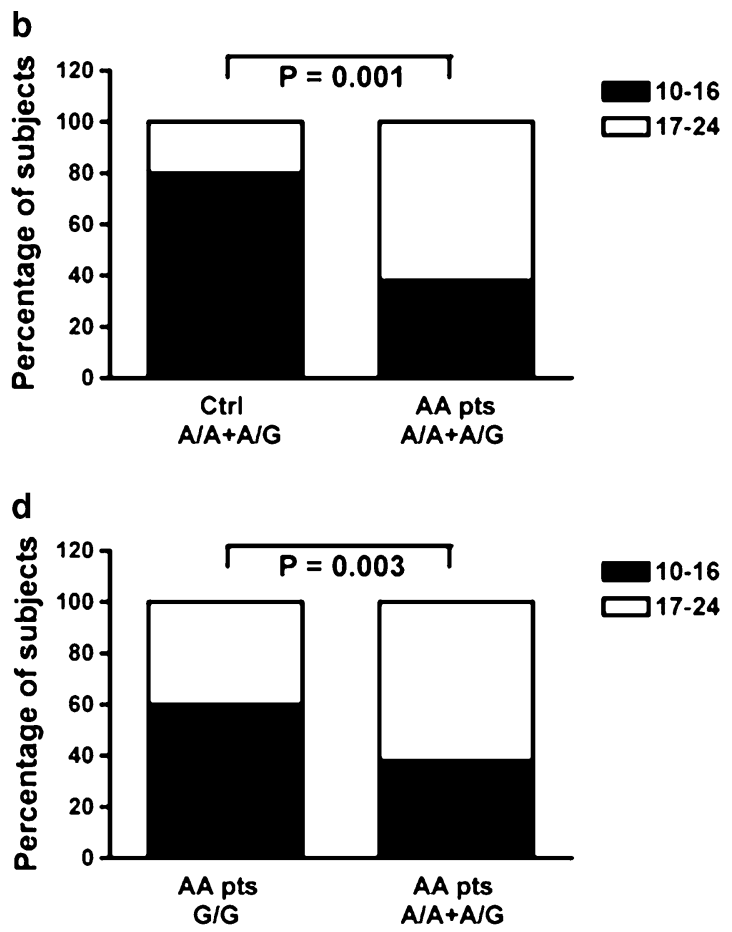

were performed comparing: a healthy controls carrying or not the A allele; b healthy controls and AA patients both carrying the A allele; c healthy controls and AA patients both carrying the G allele; d AA patients carrying or not the A allele. Each sample was run in triplicate, in parallel with no template controls. Normalization of the expression data for the FOXP3 gene was realized with GAPDH 

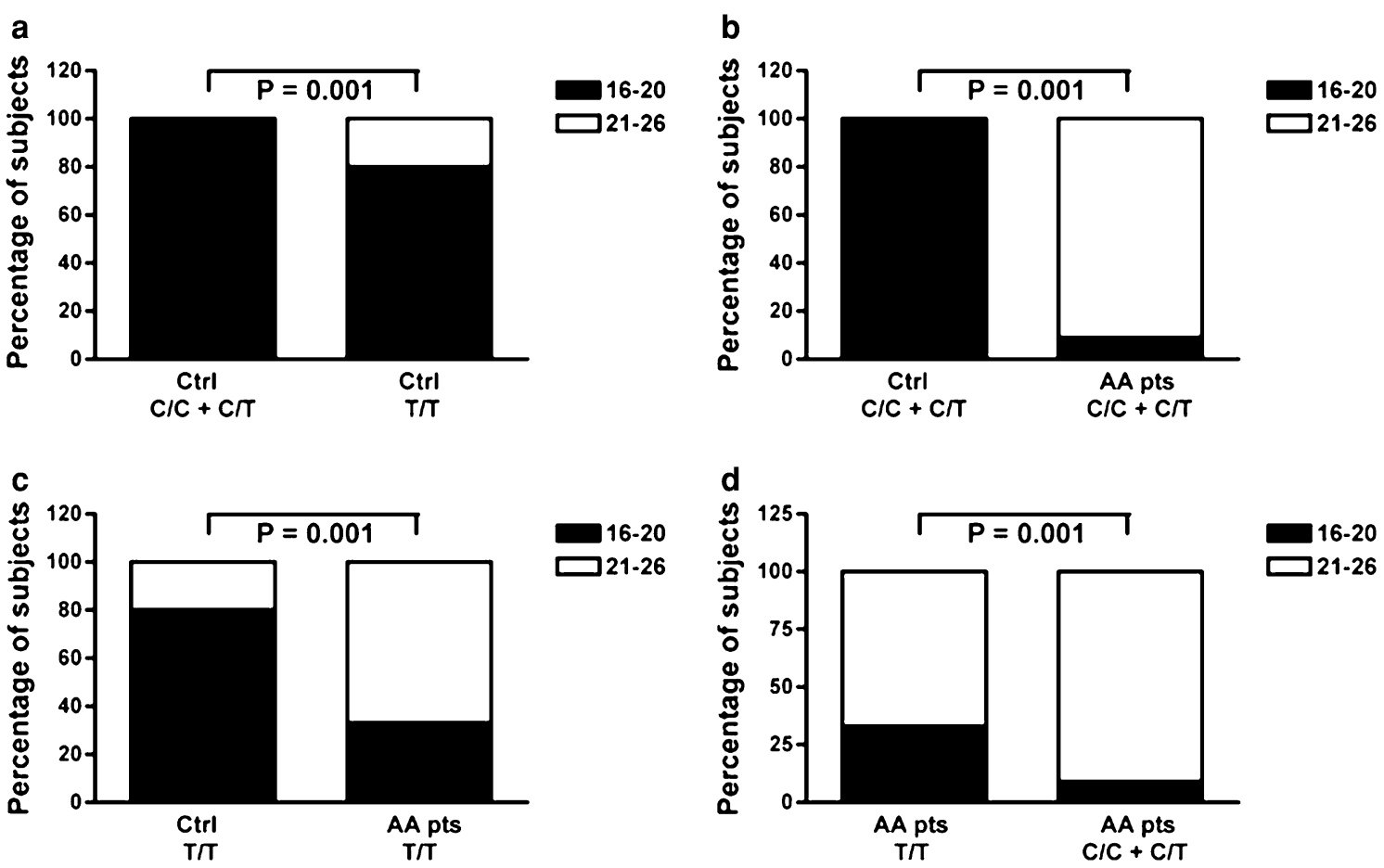

d

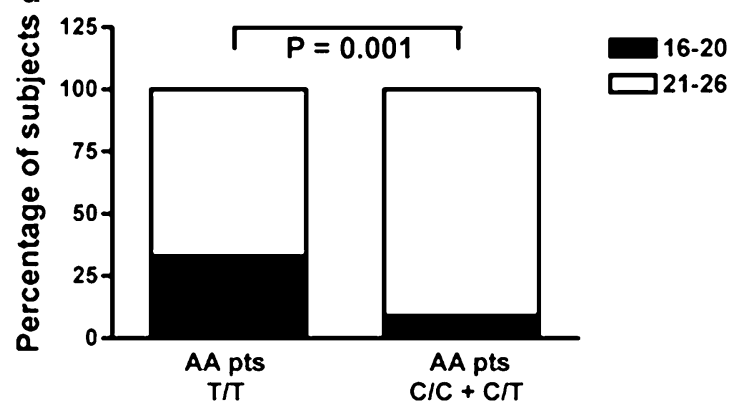

Fig. 3 Frequency of AA patients (AA pts) and healthy controls (Ctrl) carrying or not the C allelic variant of the ICOSLG rs378299 SNP with high or low ICOSLG gene expression. Analyses were performed on 24 AA patients and 20 controls. Early and late ranges of cycle numbers of DNA amplification until threshold value were the following: 16-20 (black bars) and 21-26 (white bars). Analyses

[10]. In this context, polymorphisms in the promoter region of genes coding for molecules strictly linked to the function of Treg may alter gene expression impacting on Treg activity [27]. Indeed, polymorphisms in the FOXP3 promoter gene sequence appear to confer a significant susceptibility to type 1 diabetes in the Japanese population [28] or to be associated with an increased risk of psoriasis in a Chinese population [29]. Our observation that the rs2294020 SNP in the promoter region of the FOXP3 gene is associated with AA is in line with the above considerations. Importantly, the -3675 (A) allelic variant of the rs2294020 SNP was related to a reduced FOXP3 gene expression than the corresponding $-3675(\mathrm{G})$ allelic variant, thus suggesting that a reduced FOXP3 expression predisposes to AA development through mechanisms likely involving altered Treg cell maturation and function. Indeed, no differences on FOXP3 expression were detected between healthy subjects carrying either the $-3675(\mathrm{~A})$ or the $-3675(\mathrm{G})$ allele, while AA patients with the $-3675(\mathrm{~A})$ allelic variant showed diminished gene expression than those with the corresponding $-3675(\mathrm{G})$ allele. This likely suggests that the $-3675(\mathrm{~A})$ allele, per sè considered, is not sufficient for determining a decreased gene expression but that, if associated with other factors as in AA patients, may induce the alteration.

were performed comparing: a healthy controls carrying or not the $\mathrm{C}$ allele; b healthy controls and AA patients both carrying the $\mathrm{C}$ allele; c healthy controls and AA patients both carrying the T allele; d AA patients carrying or not the $\mathrm{C}$ allele. Each sample was run in triplicate, in parallel with no template controls. Normalization of the expression data for the ICOSLG gene was realized with GAPDH

Polymorphisms of both ICOS and ICOSLG genes are associated with autoimmune diseases [30, 31]. Indeed, our data indicate an association between the rs378299509(C) allelic variant with AA. Interestingly, in AA patients, the presence of this allele was related to a reduced gene expression, event that functionally may determine an altered activation of Treg.

Interestingly, the association between the -3675 (A) allelic variant of the FOXP3 rs2294020 SNP and the -509 (C) of the ICOSLG rs378299 SNP was more frequent in AA patients than in healthy controls, and the same occurred considering also the HLA DQB1*03(DQ7) allele.

In conclusion, the present study suggests that FOXP3 and ICOSL polymorphisms, modulating the activity of these immune-related genes, may predispose to AA by decreasing FOXP3 and ICOSLG expression at mRNA level. These findings need confirmation in a wider patient population in which it would be also possible to verify whether the studied FOXP3 and ICOSL polymorphisms could be also associated with variables such as age and alopecia subtypes. Our results enrich the available knowledge on genetically determined mechanisms potentially associated with AA, supporting the usefulness of screening procedures in the search of the polymorphisms here described in order to identify subjects with increased 
susceptibility to the disease who could take advantage from preventive therapeutic intervention.

Acknowledgments This work was supported by: a) a grant from the "Associazione Nazionale Alopecia Areata"(ANAA); b) a grant from the "Compagnia di San Paolo", Torino; c) a PRIN grant from the "Ministero dell'Istruzione, dell'Università e della Ricerca“(MIUR). However, the sponsors had no role in study design; in the collection, analysis and interpretation of data; in the writing of the report; and in the decision to submit the article for publication.

Conflict of interest The authors declare that they have no competing interests.

\section{References}

1. Safavi KH, Muller SA, Suman VJ, Moshell AN, Melton LJ 3rd (1995) Incidence of alopecia areata in Olmsted County, Minnesota, 1975 through 1989. Mayo Clin Proc 70:628-633

2. Schwartz RA, Janniger CK (1997) Alopecia areata. Cutis 59:238 241

3. Kalish RS, Gilhar A (2003) Alopecia areata: autoimmunity-the evidence is compelling. J Invest Dermatol Symp Proc 8:164-167

4. Perret C, Wiesner-Menzel L, Happle R (1984) Immunohistochemical analysis of T-cell subsets in the peribulbar and intrabulbar infiltrates of alopecia areata. Acta Derm Venereol 64: 26-30

5. Tobin DJ (2003) Characterization of hair follicle antigens targeted by the anti-hair follicle immune response. J Invest Dermatol Symp Proc 8:176-181

6. Petukhova L, Duvic M, Hordinsky M, Norris D, Price V, Shimomura Y, Kim H, Singh P, Lee A, Chen WV, Meyer KC, Paus R, Jahoda CA, Amos CI, Gregersen PK, Christiano AM (2010) Genome-wide association study in alopecia areata implicates both innate and adaptive immunity. Nature 466:113-117

7. Pforr J, Blaumeiser B, Becker T, Freudenberg-Hua Y, Hanneken S, Eigelshoven S, Cuyt I, De Weert J, Lambert J, Kruse R, Nöthen MM, Betz RC (2006) Investigation of the p.Ser278Arg polymorphism of the autoimmune regulator (AIRE) gene in alopecia areata. Tissue Antigens 68:58-61

8. Megiorni F, Pizzuti A, Mora B, Rizzuti A, Garelli V, Maxia C, Carlesimo M, Fotruna MC, Delle Chiaie R, Cavaggioni G, Rossi A (2011) Genetic association of HLA-DQB1 and HLA-DRB1 polymorphisms with alopecia areata in the Italian population. $\mathrm{Br} \mathbf{J}$ Dermatol 165:823-827

9. Barahamani N, de Andrade M, Slusser J, Zhang Q, Duvic M (2002) Interleukin-1 receptor antagonist allele 2 and familial alopecia areata. J Invest Dermatol 118:335-337

10. Sakaguchi S, Yamaguchi T, Nomura T, Ono M (2008) Regulatory $\mathrm{T}$ cells and immune tolerance. Cell 133:775-787

11. Sundberg JP, Cordy WR, King LE (1994) Jr: Alopecia areata in aging $\mathrm{C} 3 \mathrm{H} / \mathrm{HeJ}$ mice. J Invest Dermatol 102:847-856

12. Hori S, Nomura T, Sakaguchi S (2003) Control of regulatory T cell development by the transcription factor Foxp3. Science 299:1057-1061

13. Fontenot JD, Gavin MA, Rudensky AY (2003) Foxp3 programs the development and function of $\mathrm{CD} 4+\mathrm{CD} 25+$ regulatory $\mathrm{T}$ cells. Nat Immunol 4:330-336

14. Khattri R, Cox T, Yasayko SA, Ramsdell F (2003) An essential role for Scurfin in $\mathrm{CD} 4+\mathrm{CD} 25+\mathrm{T}$ regulatory cells. Nat Immunol 4:337-342

15. Wu Y, Borde M, Heissmeyer V, Feuerer M, Lapan AD, Stroud JC, Bates DL, Guo L, Han A, Ziegler SF, Mathis D, Benoist C,
Chen L, Rao A (2006) FOXP3 controls regulatory T cell function through cooperation with NFAT. Cell 126:375-387

16. Chatila TA, Blaeser F, Ho N, Voulgaropoulos C, Helms C, Bowcock AM (2000) JM2 encoding a fork head-related protein, is mutated in X-linked autoimmunityallergic disregulation syndrome. J Clin Invest 106:75-81

17. Park O, Grishina I, Leung PS, Gershwin ME, Prindiville T (2005) Analysis of the Foxp3/scurfin gene in Crohn's disease. Ann N Y Acad Sci 1051:218-228

18. Oertelt S, Kenny TP, Selmi C, Invernizzi P, Podda M, Gershwin ME (2005) SNP analysis of genes implicated in T cell proliferation in primary biliary cirrhosis. Clin Dev Immunol 12:259-263

19. Owen CJ, Eden JA, Jennings CE, Wilson V, Cheetham TD, Pearce SH (2006) Genetic association studies of the FOXP3 gene in Graves' disease and autoimmune Addison's disease in the United Kingdom population. J Mol Endocrinol 37:97-104

20. Lin YC, Lee JH, Wu AS, Tsai CY, Yu HH, Wang LC, Yang YH, Chiang BL (2011) Association of single-nucleotide polymorphisms in FOXP3 gene with systemic lupus erythematosus susceptibility: a case-control study. Lupus 20:137-143

21. Dong C, Juedes AE, Temann UA, Shresta S, Allison JP, Ruddle NH, Flavell RA (2011) ICOS co-stimulatory receptor is essential for T-cell activation and function. Nature 97:97-101

22. Ito T, Hanabuchi S, Wang YH, Park WR, Arima K, Bover L, Qin FX, Gilliet M, Liu YJ (2008) Two functional subsets of FOXP3+ regulatory T cells in human thymus and periphery. Immunity 28:870-880

23. Aicher A, Hayden-Ledbetter M, Brady WA, Pezzutto A, Richter G, Magaletti D, Buckwalter S, Ledbetter JA, Clark EA (2000) Characterization of human inducible costimulator ligand expression and function. J Immunol 164:4689-4696

24. Martin-Orozco N, Li Y, Wang Y, Liu S, Hwu P, Liu YJ, Dong C, Radvanyi L (2010) Melanoma cells express ICOS ligand to promote the activation and expansion of T-regulatory cells. Cancer Res 70:9581-9590

25. Herman AE, Freeman GJ, Mathis D, Benoist C (2004) CD4+ $\mathrm{CD} 25+\mathrm{T}$ regulatory cells dependent on ICOS promote regulation of effector cells in the prediabetic lesion. J Exp Med 199:1479-1489

26. Olsen E, Hordinsky M, McDonald-Hull S, Price V, Roberts J, Shapiro J, Canfield D, Duvic M, King LE Jr, McMichael AJ, Randall VA, Turner ML, Sperling L, Whiting DA, Norris D (1999) Alopecia areata investigational assessment guidelines, National Alopecia Areata Foundation. J Am Acad Dermatol 40:242-246

27. Rizzi M, Ferrera F, Filaci G, Indiveri F (2006) Disruption of immunological tolerance: role of AIRE gene in autoimmunity. Autoimmun Rev 5:145-147

28. Bassuny WM, Ihara K, Sasaki Y, Kuromaru R, Kohno H, Matsuura N, Hara T (2003) A functional polymorphism in the promoter/enhancer region of the FOXP3/Scurfin gene associated with type 1 diabetes. Immunogenetics 55:149-156

29. Gao L, Li K, Li F, Liu L, Wang L, Zhang Z, Gao T, Liu Y (2010) Polymorphisms in the FOXP3 gene in Han Chinese psoriasis patients. J Dermatol Sci 57:51-56

30. Wang K, Baldassano R, Zhang H, Qu HQ, Imielinski M, Kugathasan S, Annese V, Dubinsky M, Rotter JI, Russell RK, Bradfield JP, Sleiman PM, Glessner JT, Walters T, Hou C, Kim C, Frackelton EC, Garris M, Doran J, Romano C, Catassi C, Van Limbergen J, Guthery SL, Denson L, Piccoli D, Silverberg MS, Stanley CA, Monos D, Wilson DC, Griffiths A, Grant SF, Satsangi J, Polychronakos C, Hakonarson H (2010) Comparative genetic analysis of inflammatory bowel disease and type 1 diabetes implicates multiple loci with opposite effects. Hum Mol Genet 15:2059-2067

31. Kim YO, Kim HJ, Kim SK, Chung JH, Hong SJ (2010) Association of the CD28/CTLA4/ICOS polymorphisms with susceptibility to rheumatoid arthritis. Clin Chem Lab Med 48:345-353 